\title{
Influence of AC Stray Current on Cathodic Disbondment of Epoxy Coatings
}

\author{
Qingmiao Ding ${ }^{1}, Z_{i l i}$ Li $^{2}$, Dilinuer Dilimulati ${ }^{1}$, Deyou Wang ${ }^{1}$, Xiaoyu Shi ${ }^{1}$ \\ ${ }^{1}$ Airport College, Civil Aviation University of China, Tianjin, P. R. China \\ ${ }^{2}$ College of Pipeline and Civil Engineering, China University of Petroleum, Qingdao, P. R. China \\ Correspondence: Qingmiao Ding, Airport College, Civil Aviation University of China, Tianjin, \\ 300300, P. R. China. Tel: 15122831876. \\ *E-mail: qmding@ cauc.edu.cn
}

doi: $10.20964 / 2021.01 .30$

Received: 18 October 2018 / Accepted: 14 March 2020 / Published: 30 November 2020

In this paper, the influence of alternating stray current (AC) on the anti-cathode disbonding performance of FBE anti-corrosion layers was studied by an electrochemical method using a high temperature simulation experiment. The results show that the AC stray current promotes the cathodic disbondment of the epoxy powder coating. Because the existence of AC stray currents could increase the replacement rate of the hydrogen evolution reaction and the anodic corrosion on the coating disbonding, the interference of the AC stray current exacerbates the degree of anode corrosion, which indirectly leads to a shorter cycle of the anode-anode reaction. Thus, the disbonding speed is increased, and the degree of cathodic disbonding of the epoxy powder coating increases as the applied AC stray current increases.

Keywords: Epoxy powder coating, AC stray current, cathodic disbonding, disbonding speed, disbonding degree

\section{$\underline{\text { FULL TEXT }}$}

(C) 2021 The Authors. Published by ESG (www.electrochemsci.org). This article is an open access article distributed under the terms and conditions of the Creative Commons Attribution license (http://creativecommons.org/licenses/by/4.0/). 